\title{
Crisis del Estado y desborde popular en el Perú
}

La existencia de dos Perúes paralelos no es un fenómeno reciente. Por un lado el Perú Oficial de las instituciones del Estado, los partidos, la banca y las empresas, los sindicatos, las universidades y colegios, las Fuerzas Armadas y la Iglesia; de los tribunales, la burocracia y el papel sellado; de la cultura exocéntrica. $Y$, por el otro, el Perú Marginado: plural y multiforme; del campesinado y la masa urbana, de las asociaciones de vecinos, los cabildos tradicionales, las rondas y varayoc; de los talleres clandestinos, los ambulantes y de las economías de trueque, de reciprocidad y de mera subsistencia; de los cuitos de los cerros, la espera de Inkarrí y la devoción a las santas y beatas no canonizadas; el Perú que conserva, adapta y fusiona innumerables tradiciones locales y regionales; bilingüe, analfabeto $y$ a veces monolingüe quechua, aymara o amazónico. Este contraste, gestado desde los primeros tiempos de la Colonia, se prolonga hasta avanzado el Perú Republicano.

Los centros coloniales de concentración del Perú Oficial, privilegiado por ser el representante de la cultura del conquistador, fueron las ciudades. En ellas, residencia de españoles, criollos y mestizos, se constituyeron las bases de un mundo político, económico, religioso y cultural que, articulado desde la metropoli, creó una imagen de unidad. Con una presencia insignificante de los representantes del pueblo conquistado y manteniendo con el Perú rural, plural y multiforme de los campesinos, apenas relaciones de explotación y dependencia señovial, el mundo de las ciudades pudo durante largo tiempo incubar la ilusión de ser el depositario de la identidad y del poder. Lima, en oposición al Guzco del Tahuantinsuyo, se constituyó desde esa época en corazón y símbolo de esa ilusión de identidad.

EI Perú Republicano heredó esta tradición centralista del Perú Oficial. El Estado Criollo, surgido de las guerras de la Independencia, sin realizar mayores intentos de incorporarse al resto del país definió su propia identidad como Estado Nacional, sobre la base del supuesto implícito de que la nación era el mundo oficial 
de las ciudades; de que su relativa unidad cultural e institucional, eran la misma unidad de la nación y de que el ajeno universo de las mayorías que persistía más allá de las ciudades representaba apenas una marginalidad intrascendente, a la que tarde o temprano, el desarrollo de la civilización haría desaparecer. La existencia de una estructura real que concentraba los poderes $y$ las participaciones en el monopolio exclusivista de las clases urbanas daba visos de realidad a esta ilusión.

El derrumbe de la economía oficial del país, como consecuencia de la derrota de 1879, dio comienzo al resquebrajamiento ideológico de la ilusión de identidad. La participación decisiva del campesinado en la Campaña de la Breña trajo a primer plano la existencia de un Perú que, ajeno al mundo urbano, se reclamaba tan peruano como éste. El desarrollo de las plantaciones azucareras y algodoneras de la costa, convirtió a parte de ese campesinado marginal, en actor protagonista de la economía oficial, al tiempo que lo proletarizaba desplazándolo hacia una condición urbana y semiurbana. Los ideólogos de la época redescubrieron el "Perú Indígena" y sacaron a la luz una identidad alternativa: se hicieron los portavoces de una "nación incásica". Pero aunque sus reflexiones reclamaron al Perí Oficial a la conciencia de que su monopolio se encontraba amenazado, no llegaron a cristalizar acciones eficientes de transformación. El Perú había cambiado poco desde los tiempos de la Colonia. Las ciudades seguían siendo reductos privilegiados de criollos y mestizos viviendo una cultura de casi exclusiva raíz europea y concentrando los instrumentos del poder. Las masas rurales marginadas seguían siendo ajenas a toda verdadera participación.

Sin embargo, dos problemas comenzaban a aflorar. La incongruencia de un Estado Nación que no representaba ni expresaba las aspiraciones de la gran mayoría de sus súbditos, extraños a esa específica definición de nacionalidad. $\mathrm{Y}$ el problema de una identidad nacional que no se expresaba en la cultura formal; frente a una cultura formal que se proponía como identidad, pero que desconocía la multiplicidad de las tradiciones populares y se desarraigaba cada día más. Estos problemas no llegaron a hacer crisis, y el horizonte de las ideologías de la época, no pudo formularlos en su verdadera dimensión.

El ingreso y difusión de las doctrinas revolucionarias europeas, a partir de los comienzos de este siglo, no hizo sino reforzar las estructuras heredadas desde los tiempos coloniales. Las utopías proveídas por socialistas y anarquistas, carecian de raíces en el suelo autóctono y contribuyeron frecuentemente a desfigurar, en la conciencia de los intelectuales y de la masa urbana en expansión, las imágenes del pasado anclino y de su realidad vigente. La aspiración del artesanado y el proletariado de la naciente izquierda era, no la 
transformación de los términos y relaciones entre lo Oficial y la nación plural de las mayorias, sino la mera captura y aprovechamiento de las estructuras de poder del Estado Oficial. Las mayorías nacionales se mantuvieron durante largo tiempo ajenas a una revolución que les resultaba tan extraña como la de la Independencia. En tanto las instituciones del Perú Oficial se expandían y consolidaban, poderosas presiones demográficas se gestaban en el medio campesino, preparando, de manera silenciosa, la explosión del medio siglo.

Las transformaciones sufridas por el Perú desde la década de 1950, han repercutido recién en forma poderosa sobre el balance y equilibrio de las relaciones entre el mundo de la oficialidad y el de las mayorías, abriendo cauces a un nuevo estilo de revolución. El desarrollo acelerado de la infraestructura de comunicaciones, los cambios en la economía, la reforma agraria y la modificación en la estructura de la tenencia de la tierra, la expansión del mercado interno, la explosión migratoria a las ciudades, han terminado no solamente por conformar la imagen de un nuevo Perú, sino por generar una nueva problemática.

Irrumpen así críticamente, las tensiones, ambigüedades e indecisiones acumuladas por más de cuatrocientos años. Las invasiones de tierras y de predios urbanos que caracterizaron la década del cincuenta, se mostraron en el curso de los años, como precursoras de más importantes y poderosas invasiones: la de los predios urbanos de la cultura oficial por la cultura andina y la de los ámbitos de la economía, la política, la educación, el mundo jurídico y la religión por los nuevos estilos impuestos por las masas en constante desborde y expansión.

En el confrontamiento inevitable de los mundos de la oficialidad $y$ el de las mayorías que trajo la multiplicación de los contactos; el mundo de lo formal, de la vieja identidad urbana criolla, dispone todavía de los instrumentos más potentes y masivos del Estado y del control de los canales oficiales de la economía, la sociedad y la cultura. Pero ha debido someterse a la infatigable y multitudinaria labor de zapa de millones de participantes en la otra sociedad. El programa implícito de asimilación por el Desarrollo, ha resultado imprevisiblemente sometido a alteración por el desarrollo espontáneo de los sectores populares, que intenta con fuerza de masas imponer sus propias condiciones.

El Perú contemporáneo ya no se presenta como un archipiélago territorial de enclaves urbanos de la oficialidad, más o menos aislados en un inmenso hinterland de marginalidad rural. Lima ya no es exclusivamente la capital reducto de lo criollo y lo mestizo monopolizando el poder y la identidad. Hoy día ha venido a convertirse en un microcosmos del macrocosmos nacional. En un espacio 
mayoritariamente dominado por la presencia migrante de representantes de toda la pluralidad y multiplicidad de situaciones que configura el pais; donde los reductos de la vieja dominancia se retraen, ocupando un espacio cada vez más disminuido. El nuevo espacio se expresa en la turbulenta confluencia de esa multiplicidad hacia una nueva cultura y sociedad unitarias en formación; aś como también en el rebalse e invasión de los estilos populares dentro de la Capital. La fuerza creciente manifestada por los modos contestatarios de la economía, la política y el gobierno, la religión y la cultura, se encuentra todavía balanceada por el poder que conservan los estilos del Perú Oficial que retiene las riendas del Estado y que controla aún la economía nacional. Los dos Perúes se interpenetran en Lima, exhibiendo en primer plano y a escala magnificada los encuentros, antagonismos e interpretaciones que se producen a escala nacional.

Los espacios físico y social de la Gapital se presentan en la nueva Lima, por primera vez en la historia del país colonial y republicano, como verídicas imágenes de los espacios físico y social de la totalidad peruana. En una extensión dominada por las barriadas en constante expansión, los tugurios, barrios decadentes y urbanizaciones populares; se presentan islotes residenciales que contrastan, por su lujo y bienestar, con la casi total carencia de servicios y la precariedad del hábitat popular urbano. En un espacio social dominado por masas que confluyen de todas las provincias aportando y combinando toda la multiplicidad de las tradiciones culturales del Perú provinciano; afloran los islotes culturales de la élite, que antes representaron la continuidad de las tradiciones criollas y mestizas coloniales, pero ahora, se rinden a patrones europeos o norteamericanos de la sociedad post-industrial. También las relaciones y dinámicas de la nueva Lima son, por primera vez, fiel reflejo de las relaciones y dinámicas de la totalidad peruana.

La población de los barrios residenciales, cada vez más extranjerizante, mantiene el control del aparato del Estado y de la institucionalidad legal. Concentra las dirigencias de partidos, la dirección de la banca y las empresas, el liderazgo cultural, las jerarquías eclesiásticas. Monopoliza los instrumentos del poder oficial en los campos de la política, la economía, la cultura y la religión. Desarrolla esfuerzos poderosos por preservar y expandir el orden formal que encarna, "incorporando" o "integrando" a éste al resto del país.

Establecido en su hereditaria condición de intermediario, el Perú Oficial sufre, sin embargo, el debilitamiento provocado por la doble crisis, nacional e internacional. La crisis económica y política mundial, socava sus esfuerzos de "integracion" y debilita su capacidad expansiva. La Lima Metropolitana y el Perú, persisten en su marginalidad urbana, económica, social y cultural, por causa de la 
incapacidad del Estado y los organismos públicos para financiar una expansión de servicios y un Programa Nacional de Desarrollo a la medida de las necesidades generadas por el crecimiento de la población y los cambios de las décadas recientes. Se enfrenta, en estas condiciones, al desborde multitudinario de las masas, que se organizan y rebalsan toda capacidad de control por parte de los mecanismos oficiales, creando las bases de una emergente estructura paralela.

Su respuesta a esta crisis del control social no hace sino agravar la situación. La complicación, la rigidez de las reglamentaciones y los procedimientos burocráticos, la obsesión de una cada vez más minuciosa normatividad legal y administrativa; sofocan y estrangulan la vida nacional y dan lugar a la aparición de incoherencias y cuellos de botella que reducen aún más la eficiencia de los aparatos de gobierno. La respuesta cultural complementaria, representada por la crec:ente especialización tecnocrática de las élites y su aumento de sofisticación en el empleo de los códigos culturales especializados de la sociedad post-industrial, ha tenido la agravante consecuencia de ahondar y abrir cada vez más la brecha que separa la cultura de las clases gobernantes, de la cultura de las masas.

La insuficiencia del aparato de gobierno para asegurar y garantizar la vigencia universal de su legalidad se pone de manifiesto en el fenómeno de la "informalización" del Perú. Disipada su autoridad y mermado su poder, el aparato del Estado comienza a girar en el vacío. Ausente la autoridad y bloqueados los canales institucionales, las masas generan bolsones semiautónomos de poder, basados en patrones asimétricos de reciprocidad rural adaptados a la situación urbana. Prescinden del Estado, y se oponen a él. Eiste se ve, gradualmente obligado a oscilar, de manera arbitraria, entre resignarse a un papel nominal o responder con una descontrolada reacción represiva.

Los términos de interacción entre el Perú Oficial y la otra socieidad que emergen se modifican en beneficio de esta última y sus representantes. De mala gana, gradualmente y como de soslayo, el Estado, sus instituciones y los miembros de las élites gobernantes, se ven obligados a aceptar la existencia de ámbitos de autogobierno en expansión: ambulantes y comercio extralegal; industrias que no pagan impuestos ni patentes; guardias y rondas vecinales y campesinas, "ajusticiamiento" por tribunales comunales; cultos populares y profetas vagabundos; droga y prostitución; amplios mercados de reclucidores de objetos :obados; guerrilleros, terrorismo y "zonas liberadas"; coimas y tramitadores. Los esfuerzos del Estado para restaurar el orden legal en este ámbito invasor se dan en un contexto de triunfalismo público, que consigue ocultar a duras penas el privado desaliento. El rechazo contra el orden que caduca se hace pe- 
netrante e invade el campo mismo de la oficialidad: las empresas más serias evaden los impuestos; grupos de profesionales y técnicos se asocian y operan en forma extralegal; los vecinos de los barrios residenciales prescinden de la Policía y se organizan para su autodefensa contra la delincuencia; los nuevos cultos encuentran adherentes entre los miembros de las clases dirigentes; las drogas y la prostitución arrastran a la jurentud de clases medias y altas; las coimas y las "comisiones" corrompen a los altos funcionarios; mientras que el terrorismo conforma dirigencia con profesores y estudiantes universitarios.

En el campo de la cultura el proceso es paralelo. A la sofisticación de la cultura cosmopolita de minorías tecnocráticas formadas en Europa y en los Estados Unidos, responden nuevos modos de adaptación y creación de la cultura popular en el contacto intenso de las tradiciones regionales y en su diálogo dinámico con los contenidos de la comunicación de masas. Aquí también la cultura de la élite se encuentra en retroceso o resulta penetrada. El huayno y la "chicha" entran en los barrios residenciales a través de nuevas clases medias de origen provinciano; las programaciones del cine, la radio y la televisión se modifican para satisfacer los gustos de la mayoría. Sectores de élite hacen también esfuerzos para adaptarse o se encierran en cenáculos y pequeños círculos. Se abre paso una nueva cultura peruana en formación. Sufre evidentemente la influencia de los contenidos de la cultura oficial, pero escapa ya de su control y gravita fuertemente hacia lo andino. Sus portadores son la masa urbana.

EI proceso en marcha corroe y disuelve la vieja ilusión criolla de la identidad nacional y pone en tela de juicio las estructuras institucioiales del Estado-Nación. Por vez primera, estos dos problemas, soterrados desde la Conquista en los sótanos de la conciencia nacional, no pueden dejar de ser planteados. El espectáculo de un Estado cuya autoridad, ya cuestionada, se reduce y cuyas instituciones se ven desertadas por las masas; y el de una cultura oficial que desconoce la lengua y la tradición mayoritaria, mientras que se expresa en lenguajes y formas de origen extranjero; abren interrogantes sobre la legitimidad del Estado y la definición de la nacionalidad. La acción creciente de las masas emergentes y la gradual cristalización de sus estilos organizativos, económicos, culturales y políticos; así como la creciente paralización del aparato del Estado por causa de la crisis económica son indicadores de que la situación se seguirá agravando y la cuestión se planteará con más urgencia en el curso de los próximos años. La respuesta no podrá formularse eficazmente en otros términos que los de una reforma profunda de la estructura del Estado y una redefinición de la identidad nacional peruana en la cultura. 
El Perú Oficial no podrá imponer otra vez sus condiciones. Deberá entrar en diálogo con las masas en desborde, para favorecer la verdadera integración de sus instituciones emergentes en el Perú que surge. Pero para esto, deberá aceptar los términos de la nueva formalidad que las masas tienen en proceso de elaboración espontánea. Sólo en esas condiciones podrá constituirse la futura legitimidad del Estado y la autoridad de la Nación. 